\title{
Frequent homozygosity in both mature and immature ovarian teratomas: a shared genetic basis of tumorigenesis
}

\author{
Olivia L Snir ${ }^{1,3}$, Maura DeJoseph ${ }^{2,3}$, Serena Wong ${ }^{1}$, Natalia Buza ${ }^{1}$ and Pei Hui ${ }^{1}$ \\ ${ }^{1}$ Department of Pathology, Yale University School of Medicine, New Haven, CT, USA and ${ }^{2}$ Office of the Chief \\ Medical Examiner, Farmington, CT, USA
}

\begin{abstract}
Although homozygosity is well documented in mature teratomas, the genetic zygosity of ovarian immature teratomas and mixed germ cell tumors is less well studied. Ten cases of mature cystic teratomas, eleven cases of grade 2 or 3 immature teratomas, and seven cases of mixed germ cell tumors with an immature teratoma component were investigated by short tandem repeat genotyping to interrogate their genetic zygosity. DNA genotyping was informative in eight mature teratomas, seven immature teratomas and six cases of mixed germ cell tumors. Out of the eight mature teratomas, five cases showed partial or complete homozygosity (63\%) with two cases demonstrating complete homozygosity (25\%). Of the immature teratomas, six cases showed partial or complete homozygosity ( $86 \%$ ) with two cases demonstrating complete homozygosity (29\%). For the mixed germ cell tumors, two cases showed partial homozygosity $(33 \%)$ and none displayed complete homozygosity. Long-term clinical follow-up was available for five immature teratomas (mean follow-up 110 months) and five mixed germ cell tumors (mean follow-up 66 months). None of the five patients with pure immature teratoma had a recurrence; in contrast, four out of five mixed ovarian germ cell tumors recurred between 4 months to 8 years $(P=0.048)$. In conclusion, both immature and mature teratomas harbor frequent genetic homozygosity suggesting a common cellular origin involving germ cells at the same developmental stage. The difference in the rate of homozygosity and tumor recurrence between pure immature teratomas and mixed germ cell tumors suggests that the two entities may involve different pathogenetic pathways and likely pursue different biological behaviors.
\end{abstract}

Modern Pathology (2017) 30, 1467-1475; doi:10.1038/modpathol.2017.66; published online 30 June 2017

Mature cystic teratoma is a benign tumor of the ovary, representing $20 \%$ of ovarian tumors in adults. ${ }^{1}$ Ovarian teratomas, by virtue of their histological appearance and common occurrence, have generated much interest in the literature. The origin of mature ovarian teratomas has been well studied through a myriad of molecular techniques, ${ }^{2-9}$ and these tumors are thought to arise from germ cells. Most commonly, mature teratomas arise from germ cells that have undergone meiosis I and display homozygosity, in contrast to other somatic cells that are heterozygous with distinct maternal and paternal alleles at a given genetic locus. The homozygosity

Correspondence: Professor P Hui, Department of Pathology, Yale School of Medicine, BML254B, 310 Cedar Street, New Haven, CT 06510, USA.

E-mail: pei.hui@yale.edu

${ }^{3}$ These two authors contributed equally to this work.

Received 18 February 2017; revised 7 May 2017; accepted 8 May 2017; published online 30 June 2017 seen in mature teratomas may be complete or partial, by virtue of crossing over events. Not all mature teratomas display a homozygous genotype; approximately $35 \%$ show a heterozygous genome arising in a premeiotic germ cell or following meiosis I failure. ${ }^{6-8}$

Immature teratomas comprise approximately $1 / 3$ of malignant germ cell tumors ${ }^{10}$ and are the second most common malignant ovarian germ cell tumor. ${ }^{1}$ Immature teratomas are thought to arise by a similar mechanism as their benign, mature counterparts; ${ }^{11}$ however, strong supporting genetic data are lacking. A few studies have analyzed polymorphic loci in a small number of malignant teratomas and have demonstrated cases with complete or partial homozygosity, ${ }^{12}$ including one case of an immature teratoma with complete homozygosity. ${ }^{13}$ In contrast to these studies, others have investigated various immature tissue elements and shown that the immature component may be heterozygous in cases in which the mature component displays 
homozygosity. ${ }^{14}$ Moreover, immature teratoma can be a component of a mixed malignant germ cell tumor ${ }^{15,16}$ as in their testicular counterpart. ${ }^{17}$ Interestingly, studies have shown the majority of pure immature teratomas are diploid ${ }^{17}$ and lack the $12 p$ abnormalities that are often seen in ovarian mixed germ cell tumors, ${ }^{16,18,19}$ suggesting that mixed germ cell tumors and pure immature teratomas may arise through different molecular genetic pathogeneses.

With improved molecular techniques, it is now possible to rapidly assess more informative polymorphism loci by short tandem repeat analysis than were previously available. In this study, we investigated the status of genetic zygosity by short tandem repeat genotyping in a cohort of seven pure immature teratomas, six mixed germ cell tumors with immature teratomatous component and eight mature teratomas with a goal to gain further insight into the pathogenesis of immature teratomas.

\section{Materials and methods}

\section{Case Selection}

Ten cases of ovarian mature teratomas, eleven cases of ovarian immature teratomas, and seven cases of ovarian mixed germ cell tumors with immature teratoma component were initially collected from our departmental pathology archives. Histological and immunohistochemical slides were reviewed by three pathologists (OLS, NB and $\mathrm{PH}$ ) to confirm diagnosis, to assess grade of the immature teratomas, to confirm tumor components in the mixed germ cell tumors, to assess the histological composition of metastases, and to determine the tumor stage. Immature teratomas were graded from grade 1 (G1) to grade 3 (G3) according to a three-tiered grading system. ${ }^{1,20,21}$ In brief, cases are assigned grade 1 if immature neuroepithelial tissue occupies $<1$ low power field $(\times 40)$ in any slide. Grade 2 is assigned if similar elements occupy 1-3 low power fields on any single slide. Tumors with $>3$ low power fields of immature neuroepithelial tissue on any single slide are assigned grade 3 . All malignant cases were staged according to the 7th edition of the American Joint Committee on Cancer (AJCC) staging guidelines. $^{22}$ Target tissue areas for tissue genotyping were selected. Demographic and clinical followup data were obtained by review of clinical records. The study was approved by the Institutional Review Board.

\section{Tissue Dissection and DNA Extraction}

Formalin-fixed, paraffin-embedded blocks containing distinct areas of teratoma and normal tissue were selected for each case. For pure immature teratomas and mixed germ cell tumors, areas with the highest percentage of immature neuroectodermal elements were selected. One hematoxylin and eosin (H\&E)- stained section and additional unstained sections were created on glass slides from the formalin-fixed, paraffin-embedded tissue blocks. Areas of teratoma and normal tissue were confirmed by H\&E-stained slide review and corresponding tissues from the unstained slides were scraped with a sterile scalpel into separate microcentrifuge tubes. DNA was extracted by hydrothermal pressure method of simultaneous deparaffinization and lysis of formalin-fixed paraffin-embedded tissue followed by conventional column purification to obtain high-quality DNA. ${ }^{23}$

\section{Short Tandem Repeat Genotype Analysis}

Tissue genotyping using PowerPlex 16 System (Promega Corporation, Madison, WI, USA) was performed by multiplex PCR at 15 short tandem repeat loci according to manufacturer instruction. One microliter of the PCR product was mixed with $13 \mu \mathrm{l}$ of Hi-Di and $0.5 \mu \mathrm{l}$ sizing marker (GeneScan-500LIZ, Applied Biosystems), followed by capillary electrophoresis on an ABI3130 platform. Data collection and analysis were performed using GeneMapper software version 3.7 (Applied Biosystems, Foster City, California, USA). PCR products were identified by fluorescent color and expected size range. Normal tissue genotypes were reviewed and loci were considered informative if two distinct alleles at a given locus were observed. The informative loci were then scored to determine tumor genotype for each locus as homozygous or heterozygous if the mature or immature teratoma displayed one or two alleles at the given locus, respectively. Cases that demonstrated homozygosity at all informative loci were defined as complete homozygosity. Cases that displayed homozygosity at greater than $30 \%$ of informative loci but were not completely homozygous were defined as partial homozygosity. Cases with less than $30 \%$ homozygous loci were deemed heterozygous.

\section{Statistical Analysis}

Continuous numerical variables (eg, patient age) were analyzed by the two-tailed $t$-test for two independent means, while categorical variables (eg, tumor recurrence) were analyzed by two-tailed Fisher exact test. $P$-value of less than 0.05 was considered statistically significant.

\section{Results}

Among the initial 10 cases of mature ovarian teratomas, eleven cases of pure immature ovarian teratomas, and seven cases of mixed malignant germ cell tumors with an immature teratomatous component, informative DNA genotyping data were obtained in eight mature teratomas, seven immature teratomas, and six mixed germ cell tumors. Seven cases were excluded due to poor tissue quality or 
Table 1 Clinicopathological characteristics of cases with informative genotyping

\begin{tabular}{|c|c|c|c|c|c|c|c|c|}
\hline Case & Age & Diagnosis & $\begin{array}{l}\text { Grade of } \\
\quad I T\end{array}$ & Size & $\begin{array}{l}\text { Extra-ovarian } \\
\text { involvement }\end{array}$ & $\begin{array}{l}\text { Components in } \\
\text { metastases }\end{array}$ & Stage $^{\mathrm{a}}$ & Follow-up \\
\hline 1 & 48 & Immature teratoma & 3 & $11 \mathrm{~cm}$ & Yes & Immature teratoma & IIIC & No recurrence (53 months) \\
\hline 2 & 27 & Immature teratoma & 2 & $15 \mathrm{~cm}$ & No & - & IA & No recurrence (86 months) \\
\hline 3 & 11 & Immature teratoma & 3 & $22 \mathrm{~cm}$ & No & - & IA & No recurrence (53 months) \\
\hline 4 & 9 & Immature teratoma & 2 & $8.5 \mathrm{~cm}$ & Yes & Malignant cells ${ }^{\mathrm{b}}$ & IIC & No recurrence (148 months) \\
\hline 5 & 34 & Immature teratoma & 2 & $16 \mathrm{~cm}$ & No & - & IA & No recurrence (208 months) \\
\hline 6 & 22 & Immature teratoma & 2 & $22 \mathrm{~cm}$ & Yes & Mature teratoma & IIIC & Not available \\
\hline 7 & 24 & Immature teratoma & 3 & $38 \mathrm{~cm}$ & No & 一 & IA & Not available \\
\hline 8 & 48 & $\begin{array}{l}\text { MGCT with IT and } \\
\text { YST ( }<5 \% \text { YST) }\end{array}$ & 3 & $18 \mathrm{~cm}$ & Yes & Mature teratoma & IIIB & $\begin{array}{l}\text { Recurrence at } 31 \text { months with } \\
\text { IT }\end{array}$ \\
\hline 9 & 20 & $\begin{array}{l}\text { MGCT with IT and } \\
\text { EC }(\sim 80 \% \text { EC })\end{array}$ & 3 & $一^{\mathrm{c}}$ & Yes & Mature teratoma & IIIC & $\begin{array}{l}\text { Recurrence at } 4 \text { months with } \\
\text { atypical cells }{ }^{b}\end{array}$ \\
\hline 10 & 12 & $\begin{array}{l}\text { MGCT with IT and } \\
\text { YST ( }<5 \% \text { YST) }\end{array}$ & 3 & $26 \mathrm{~cm}$ & Yes & Immature teratoma & IIIC & $\begin{array}{l}\text { Recurrence at } 3 \text { months and at } \\
25 \text { months with mature } \\
\text { teratoma }\end{array}$ \\
\hline 11 & 19 & $\begin{array}{l}\text { MGCT with IT and } \\
\text { YST }(<5 \% \text { YST) }\end{array}$ & 3 & $17 \mathrm{~cm}$ & No & - & IA & Not available \\
\hline 12 & 18 & $\begin{array}{l}\text { MGCT with IT and } \\
\text { YST ( }<5 \% \text { YST) }\end{array}$ & 3 & $18 \mathrm{~cm}$ & Yes & IT and YST & IIIC & $\begin{array}{l}\text { Recurrence at } 96 \text { months with } \\
\text { mature teratoma }\end{array}$ \\
\hline 13 & 27 & $\begin{array}{l}\text { MGCT with IT and } \\
\text { YST ( }<5 \% \text { YST) }\end{array}$ & 3 & $22 \mathrm{~cm}$ & No & - & IA & No recurrence (196 months) \\
\hline 14 & 28 & Mature teratoma & - & $108 \mathrm{gm}^{\mathrm{d}}$ & - & - & - & - \\
\hline 15 & 67 & Mature teratoma & - & $8 \mathrm{~cm}$ & - & - & - & - \\
\hline 16 & 33 & Mature teratoma & - & $14 \mathrm{~cm}$ & - & - & - & - \\
\hline 17 & 27 & Mature teratoma & - & $4.5 \mathrm{~cm}$ & - & - & - & - \\
\hline 18 & 18 & Mature teratoma & - & $6 \mathrm{~cm}$ & - & - & - & - \\
\hline 19 & 54 & Mature teratoma & - & $12 \mathrm{~cm}$ & - & - & - & - \\
\hline 20 & 16 & Mature teratoma & - & $57 \mathrm{gm}^{\mathrm{d}}$ & - & & - & - \\
\hline 21 & 35 & Mature teratoma & - & $4 \mathrm{~cm}$ & - & & - & - \\
\hline
\end{tabular}

Abbreviations: EC, embryonal carcinoma; IT, immature teratoma; MGCT, mixed germ cell tumor; YST, yolk sac tumor.

apathologic Staging - AJCC, 7th edition, 2010.

${ }^{\mathrm{b}}$ Cytology only.

${ }^{\mathrm{c}}$ Size cannot be determined pathologically and only biopsies submitted.

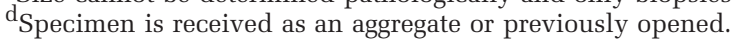

PCR amplification failure in the target tissue components (either normal tissue or teratoma).

The clinical and pathological characteristics of the twenty-one cases with informative genotyping are presented in Table 1. The age of patients at presentation ranged from 16 to 67 years (mean $=35$ years) for patients with mature teratomas, 9 to 48 years (mean $=25$ years) for patients with pure immature teratomas, and 12 to 48 years (mean $=24$ years) for patients with mixed germ cell tumors. The age difference between the pure immature teratoma and mixed germ cell tumor groups was not statistically significant. The tumor size ranged from 4 to $14 \mathrm{~cm}$ for mature teratomas, 8.5 to $38 \mathrm{~cm}$ for immature teratomas, and 17 to $22 \mathrm{~cm}$ for mixed germ cell tumors. All immature teratomas and mixed germ cell tumors were unilateral; in one case (case 1), the contralateral ovary contained a mature cystic teratoma. Seven cases had extra-ovarian tumor involvement at initial presentation (Table 1), including three cases of pure immature teratomas and four cases of mixed germ cell tumors. The pathological stage of the cases ranged from stage IA to stage IIIC for both pure immature teratomas and mixed germ cell tumors. None of the patients with immature teratomas or mixed germ cell tumors had a prior history of malignancy.

Histologically, all seven immature teratomas were high grade-grade 2 or 3 tumors (Figures 1 and 2). All six mixed germ cell tumors contained a grade 3 immature teratoma component and the additional tumor components were either yolk sac tumor (five cases, Figure 3) or embryonal carcinoma (one case). Five mixed germ cell tumors contained predominantly teratoma component with yolk sac tumor as a minor component. One mixed germ cell tumor contained primarily embryonal carcinoma with teratoma as a minor element (Table 1). The yolk sac tumor component in all relevant cases showed characteristic histological features and positive AFP immunohistochemistry. All immature teratomas and mixed germ cell tumors also contained mature teratomatous elements, although in varying proportions (Figure 2). For cases with extra-ovarian involvement, the metastases consisted of mature teratoma in three cases, immature teratoma in two cases, and both immature teratoma and yolk sac tumor in one case. In one case, the extra-ovarian involvement was documented by the presence of tumor cells in a pelvic cytology specimen. 

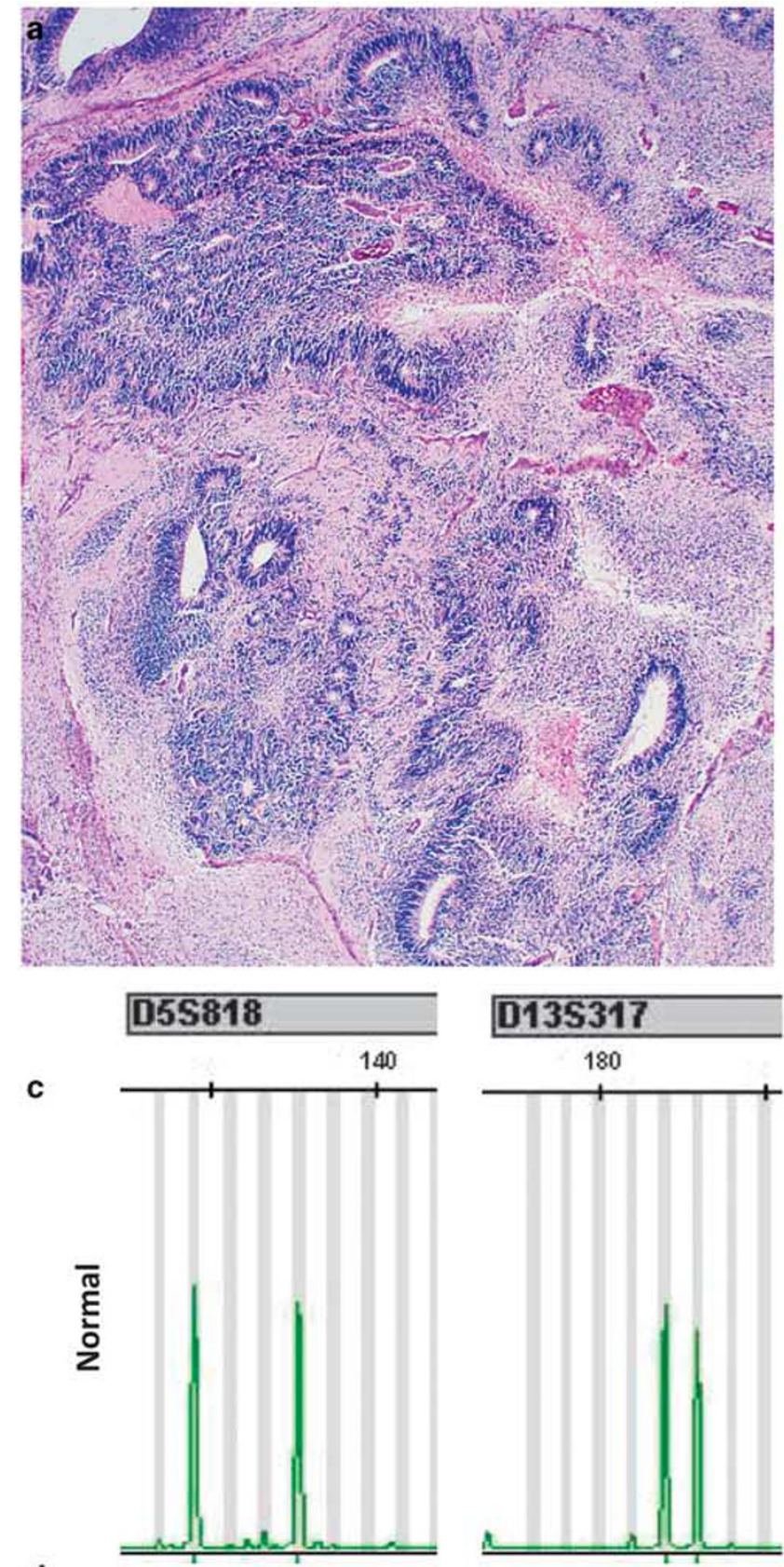

d

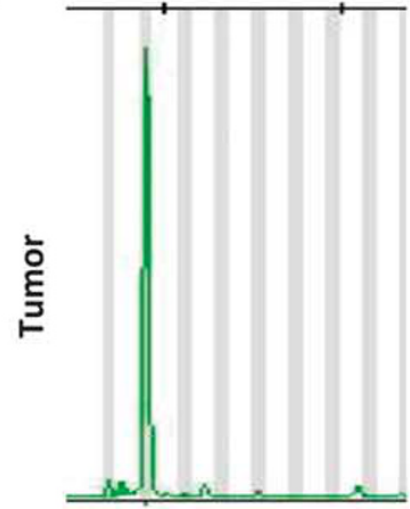

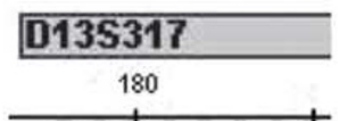
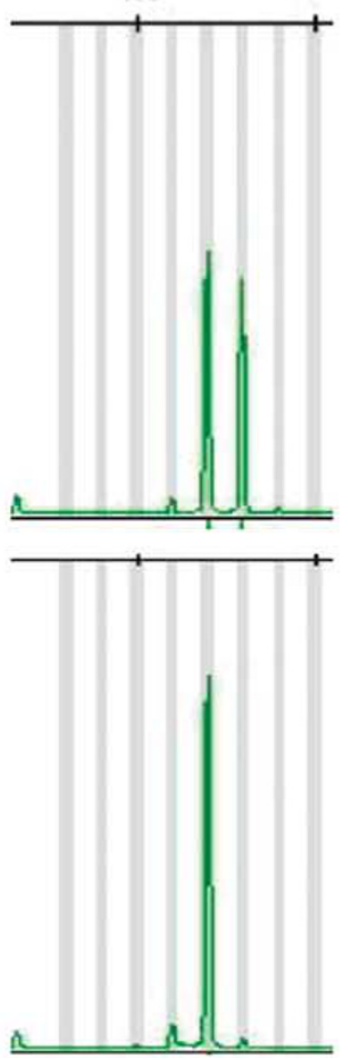
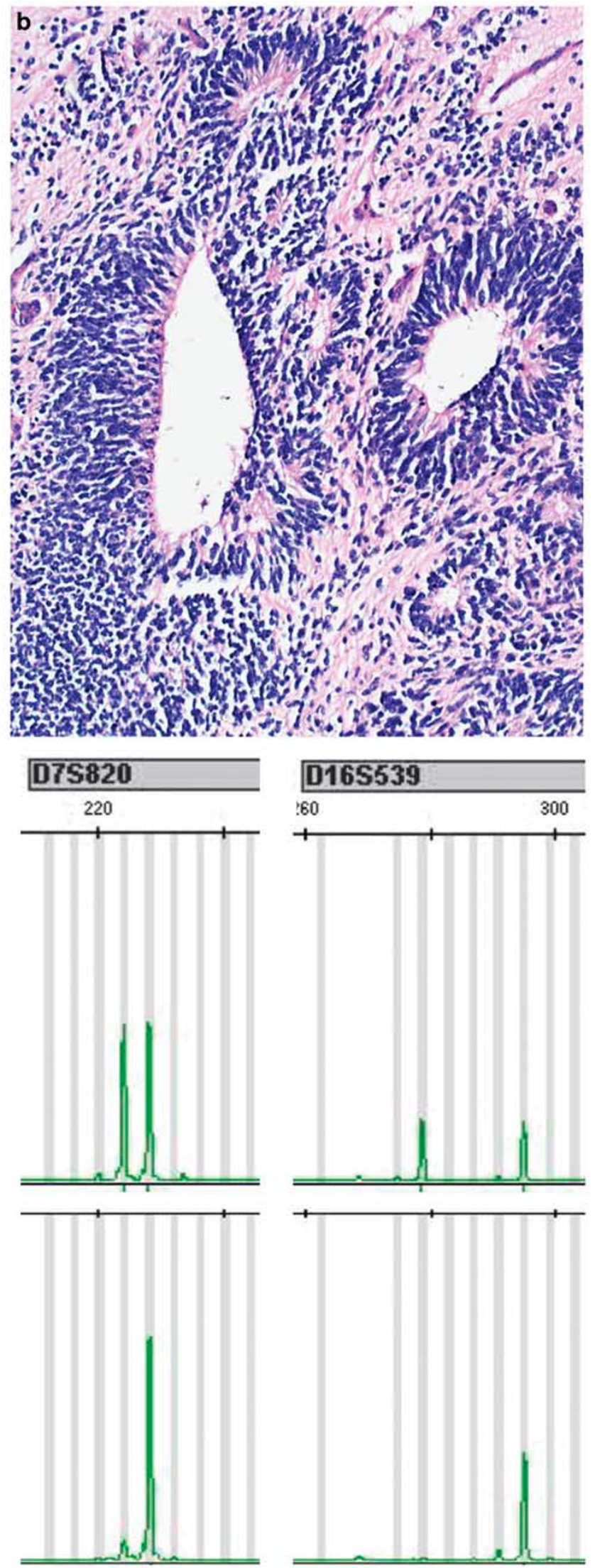

Figure 1 Ovarian immature teratoma (G3) with complete homozygosity (Case 7). (a) Low power of area of immature teratoma used for molecular analysis (HE, × 40). (b) Immature neuroepithelial tubules are easily identified (HE, × 200). Genotyping information with four informative (heterozygous) loci seen in normal tissue (c). The immature component (d) displays complete homozygosity at informative loci. HE, hematoxylin and eosin. 
Table 2 summarizes the informative genotyping data of immature teratomas, mixed germ cell tumors, and mature teratomas. All informative cases displayed between 8 and 14 heterozygous short tandem repeat loci in the corresponding normal tissue. Six of the seven cases $(86 \%)$ of immature
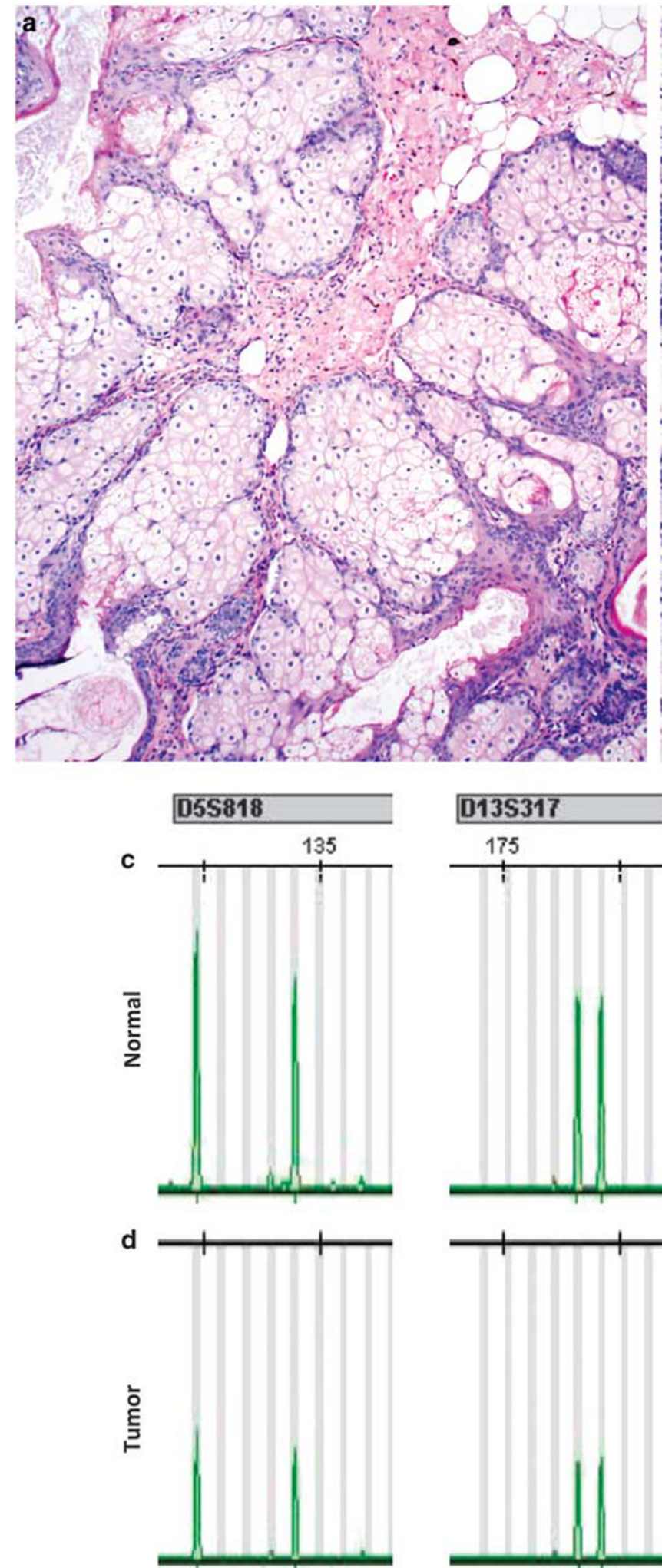
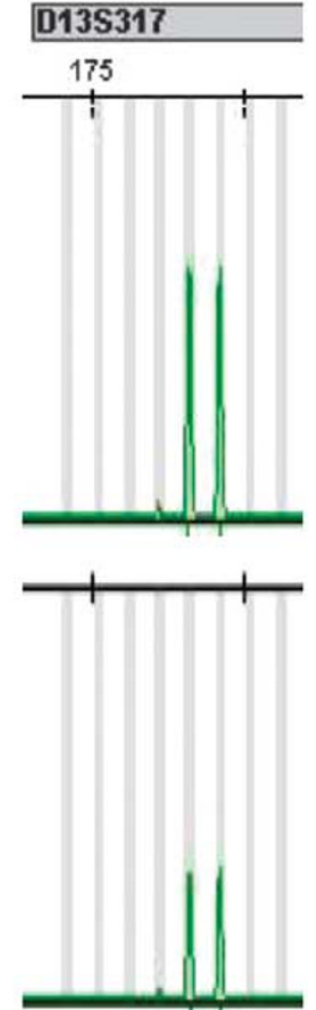
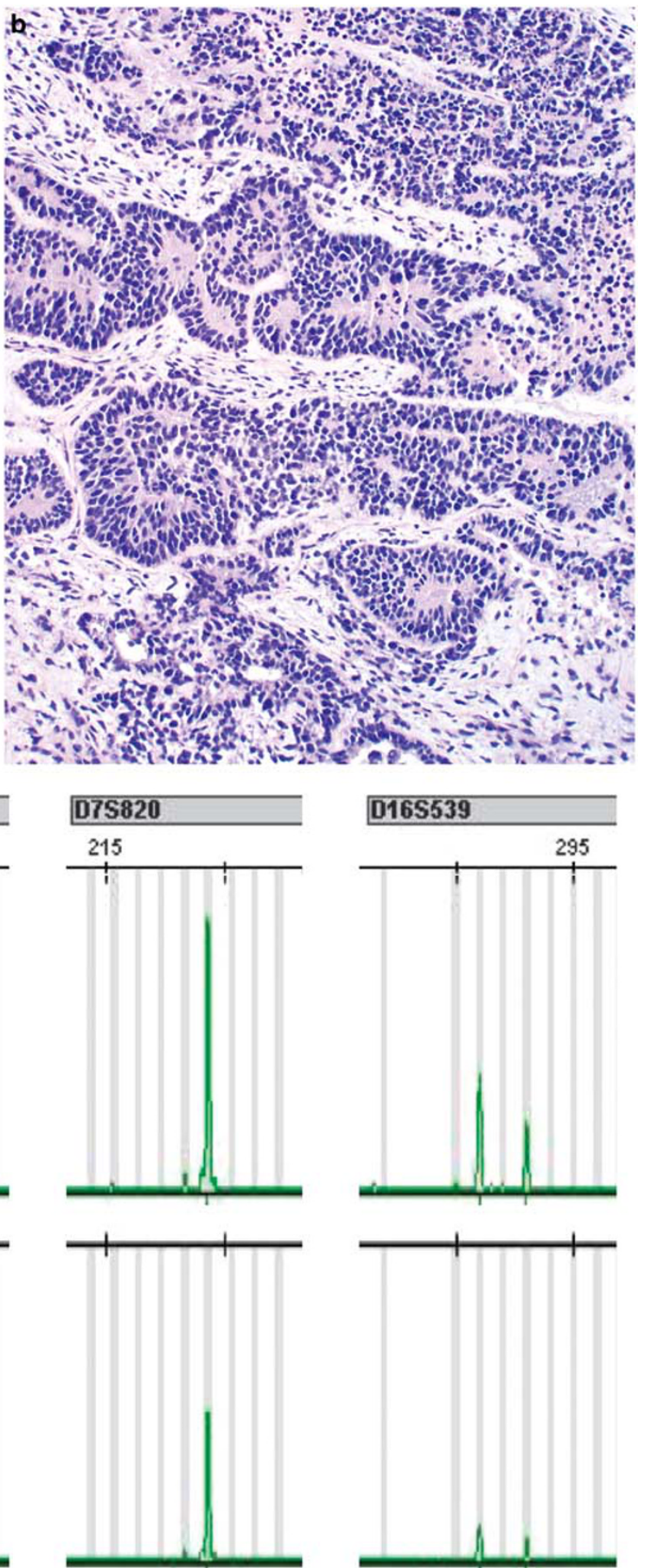

Figure 2 Ovarian immature teratoma (G3) with heterozygosity (Case 1). (a) Areas of the tumor with mature elements (HE, × 100). (b) Foci of immature neuroectodermal elements $(\mathrm{HE}, \times 200)$. Three of four informative loci are heterozygous in normal tissue (c) with matching heterozygosity seen in the immature teratoma (d). HE, hematoxylin and eosin. 
a
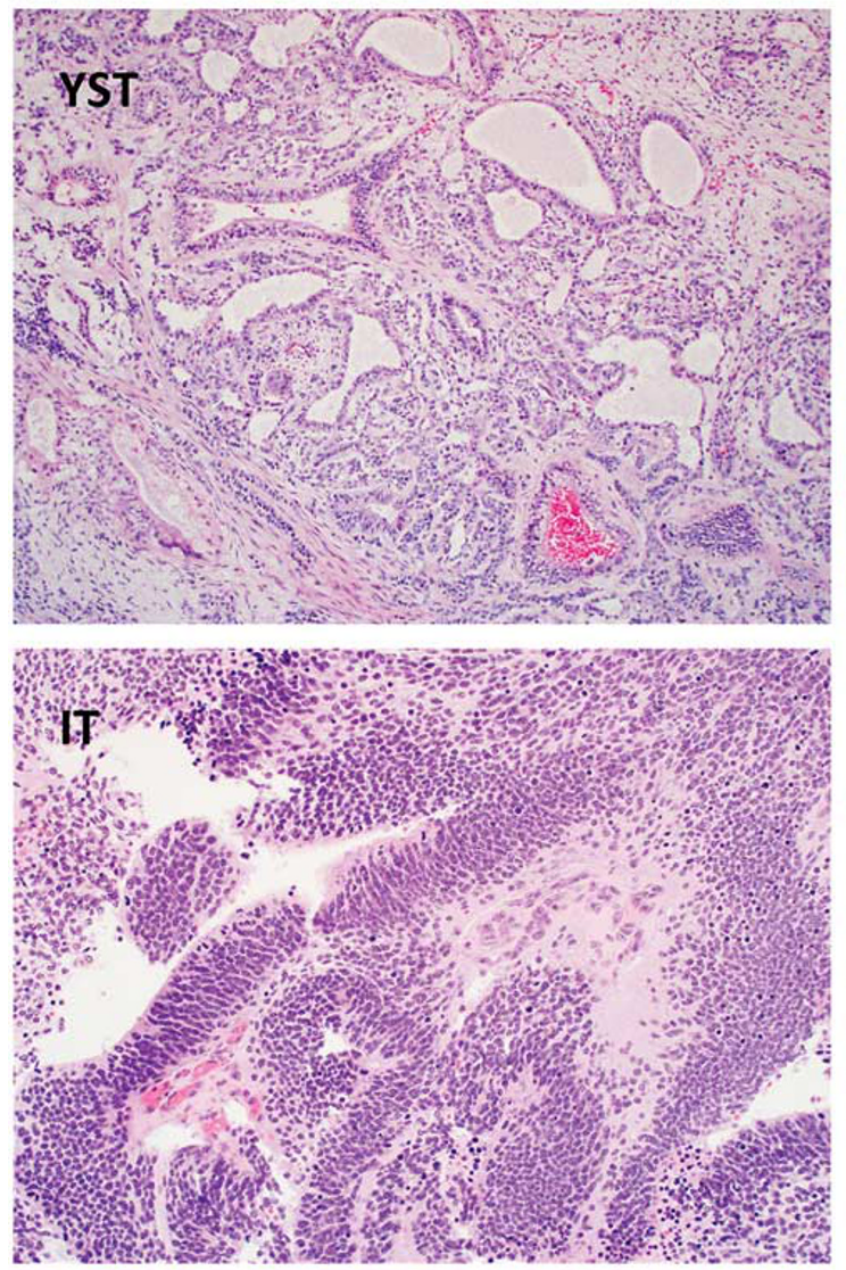
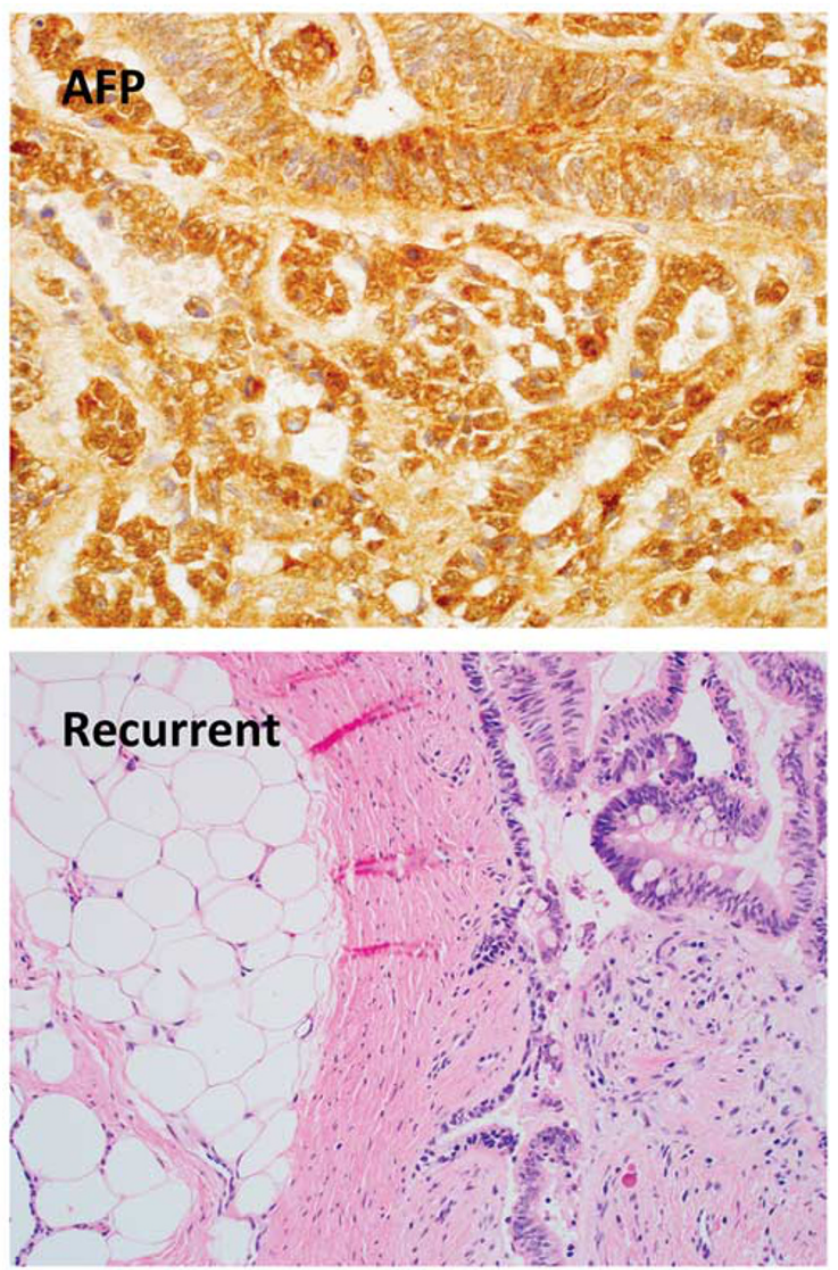

Figure 3 Mixed ovarian germ cell tumor with immature teratoma (G3) and yolk sac tumor components (Case 12). (a) Histological features: Area of YST component (HE, $\times 100)$. YST component demonstrating positivity for AFP immunohistochemistry (AFP) (AFP Immunohistochemical stain, $\times 400$ ). Immature neuroectodermal elements (IT) (HE, 200x), and recurrent tumor with mature teratoma histology (recurrent) (HE, $\times 200)$. (b) Matching genotyping profile between the immature teratoma component at initial diagnosis and the recurrent teratoma. Four informative heterozygous loci are shown in normal fallopian tube tissue (top). The immature teratoma component at initial diagnosis (middle) and the recurrent teratoma (bottom) display matching homozygosity at the four depicted loci. HE, hematoxylin and eosin; YST, yolk sac tumor.

teratomas displayed homozygosity with complete homozygosity in two cases and partial homozygosity in four cases. Partial homozygosity was seen in two out of six $(33 \%)$ mixed germ cell tumors including one demonstrating near-complete homozygosity (case 13, Table 2). Complete homozygosity was not seen in any mixed germ cell tumors. As expected, five out of eight $(63 \%)$ mature teratomas showed homozygosity including two cases of complete homozygosity and three cases of partial homozygosity (Table 3). There was no statistically significant difference in the age of patients with heterozygous teratomas (mean age $=43$ years) versus those with homozygous teratomas (mean age $=30$ years) for any tumor type.

One mixed germ cell tumor recurred with only mature teratoma histology (Figure 3, case 12). Tissue samples from both the initial diagnosis and recurrence were available for genotyping analysis. Identical partial homozygosity-with four homozygous loci among the 11 informative ones-was observed between the immature teratoma component of the primary tumor and the recurrent tumor (Figure 3).

Long-term clinical follow-up (Table 1) was available for five immature teratomas (53 to 208 months with mean of 110 months) and five mixed germ cell tumors (3 to 196 months with mean 66 months). None of the five patients with pure immature teratoma had a recurrence. Four of five $(80 \%)$ mixed ovarian germ cell tumors with available follow-up recurred with the time to recurrence varying from 4 months to 8 years (Table 1). The recurrent tumors were mature teratomas in two cases and immature teratoma in one case. Tumor recurrence was documented by positive cytology in one case (Table 1). 


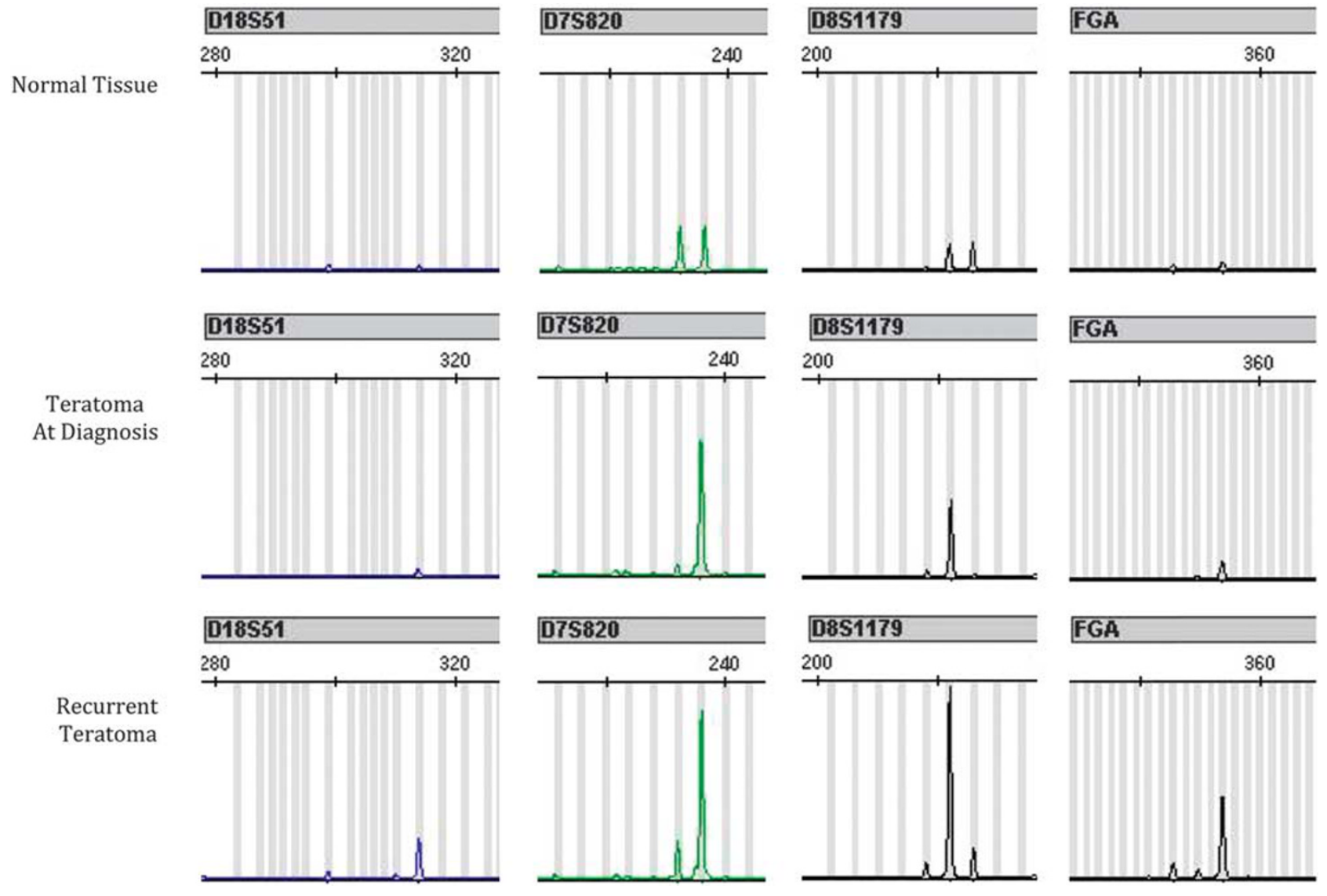

Figure 3 Continued.

The difference of recurrence rates between immature teratomas and mixed germ cell tumors is statistically significant $(P=0.048)$.

\section{Discussion}

The germ cell origin of mature teratoma has been well documented in the literature for nearly half a century. ${ }^{2-6,9}$ Although diploid with 46 XX karyotype in most cases, the pathogenesis of ovarian mature teratoma involves ovarian germ cells arrested at various stages of meiosis. Previous studies using various approaches including electrophoretic banding patterns, ${ }^{4}$ enzyme polymorphisms, ${ }^{5}$ and centromeric hetermorphisms $s^{6}$ indicate that the majority of ovarian mature teratomas develop from ovarian oocytes after completion of meiosis I with failure of meiosis II, therefore containing a homozygous chromosome set that is genetically distinct from the diploid heterozygous genome in somatic cells. However, an estimated $35 \%$ of ovarian mature teratomas may arise as a result of meiosis I failure or mitotic division of premeiotic germ cells, consequently inheriting a heterozygous biallelic genome similar to that of the somatic cells. ${ }^{6,7,24}$ Corroborating the existing data, in our study $63 \%$ of mature teratomas displayed partial or complete homozygosity with the remaining $37 \%$ showing heterozygosity. There was no statistical difference in patient age between heterozygous and homozygous mature teratomas.

Although genetic data are limited, a few previous studies suggested that immature teratomas have a pathogenesis similar to mature teratomas based on the presence of homozygosity. ${ }^{11}$ A series of six immature teratomas previously revealed homozygosity in $67 \%^{11}$ of tumors and a separate study showed complete homozygosity in a grade 3 immature teratoma. ${ }^{13}$ Among 7 informative pure immature teratomas in our study, $86 \%$ revealed homozygosity including 2 cases $(29 \%)$ with complete homozygosity and 4 cases $(57 \%)$ with partial homozygosity. Such similar frequency of homozygosity between immature and mature teratomas implies a common pathogenesis. It is interesting to note that none of the pure immature teratoma cases recurred in our study.

Six of the seven mixed germ cell tumors with immature teratoma and yolk sac tumor or embryonal carcinoma components were successfully analyzed by short tandem repeat genotyping. Two of these cases demonstrated partial homozygosity and none showed complete homozygosity. While the difference in zygosity between mixed germ cell tumors and pure immature teratomas failed to reach 
Table 2 Teratoma genotyping result of informative cases

\begin{tabular}{|c|c|c|c|}
\hline Case & Diagnosis & Number of homozygous alleles ${ }^{\mathrm{a}}$ & Interpretation \\
\hline 1 & IT & $0 / 8$ & Heterozygous \\
\hline 2 & IT & $3 / 9$ & Partial homozygosity \\
\hline 3 & IT & $4 / 9$ & Partial homozygosity \\
\hline 4 & IT & $8 / 14$ & Partial homozygosity \\
\hline 5 & IT & $5 / 8$ & Partial homozygosity \\
\hline 6 & IT & $11 / 11$ & Complete homozygosity \\
\hline 7 & IT & $12 / 12$ & Complete homozygosity \\
\hline 8 & MGCT: IT \& YST & $1 / 9$ & Heterozygous \\
\hline 9 & MGCT: IT \& EC & $1 / 8$ & Heterozygous \\
\hline 10 & MGCT: IT \& YST & $3 / 12$ & Heterozygous \\
\hline 11 & MGCT: IT \& YST & $3 / 12$ & Heterozygous \\
\hline 12 & MGCT: IT \& YST & 4/11 & Partial homozygosity \\
\hline 13 & MGCT: IT \& YST & $11 / 12$ & Partial homozygosity \\
\hline 14 & MT & 0/12 & Heterozygous \\
\hline 15 & MT & $1 / 10$ & Heterozygous \\
\hline 16 & MT & $2 / 9$ & Heterozygous \\
\hline 17 & MT & $3 / 10$ & Partial homozygosity \\
\hline 18 & MT & $3 / 8$ & Partial homozygosity \\
\hline 19 & MT & $9 / 10$ & Partial homozygosity \\
\hline 20 & MT & $12 / 12$ & Complete homozygosity \\
\hline 21 & MT & $16 / 16^{\mathrm{b}}$ & Complete homozygosity \\
\hline
\end{tabular}

Abbreviations: EC, embryonal carcinoma; IT, immature teratoma; MGCT, mixed germ cell tumor, MT, mature teratoma, YST, yolk sac tumou. ${ }^{\mathrm{a}}$ The denominator in each case is the number of informative alleles; that is, the number of heterozygous alleles in normal tissue.

${ }^{b}$ No molecular data available for normal tissue; however, the teratoma displays complete homozygosity.

Table 3 Summary of genotyping data by tumor type (informative cases only)

\begin{tabular}{|c|c|c|c|c|}
\hline Tumor type & Heterozygosity & Partial homozygosity & Complete homozygosity & Percentage with homozygosity \\
\hline Mature teratoma & 3 & 3 & 2 & $63 \%(5 / 8)$ \\
\hline Immature teratoma & 1 & 4 & 2 & $86 \%(6 / 7)$ \\
\hline Mixed germ cell tumora & 4 & 2 & 0 & $33 \%(2 / 6)$ \\
\hline Total & 8 & 9 & 4 & $62 \%(13 / 21)$ \\
\hline
\end{tabular}

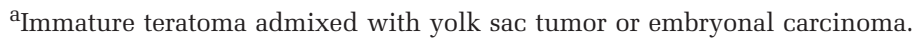

statistical significance $(P=0.052)$, such difference in the frequency of homozygosity suggests that mixed germ cell tumors with an immature teratoma component may involve a different pathogenesis from that of pure immature teratoma. Such hypothesis is supported by previous investigations, ${ }^{16,18,19}$ in which pure immature teratomas typically harbor fewer genetic alterations detectable by comparative genomic hybridization and lacked 12p abnormalities characteristically seen in mixed germ cell tumors.

Another striking difference between pure immature teratomas and mixed germ cell tumors in our study was the tumor recurrence rate. While none of the pure immature teratomas with follow-up of 53 to 208 months (mean of 110 months) recurred, four of five mixed germ cell tumors recurred 3 to 196 months (mean of 66 months) after the initial diagnosis. Such difference in tumor recurrence is statistically significant between the two tumor types $(P=0.048)$. Indeed, one previous study concluded that the overall survival rate of immature teratomas in pediatric population was related to the presence of yolk sac tumor component and pure immature teratoma had a very good prognosis. ${ }^{25}$ Our finding further highlights the pathobiological difference between pure immature teratomas and mixed ovarian germ cell tumors with an immature teratoma component. Therefore, histological examination of a primary ovarian immature teratoma for the presence of yolk sac tumor and embryonal carcinoma is clinically relevant.

Immature teratomas and mixed germ cell tumors may present with extra-ovarian involvement or recurrence of exclusively mature teratomatous tissue types including so-called gliomatosis peritonei (multiple foci of mature glial tissue involving the peritoneum). In contrast to a previous study where the genetic profile of the gliomatosis was found to be different from that of the concurrent ovarian teratoma, ${ }^{26}$ identical partial homozygosity was observed in the immature teratoma component of a mixed germ cell tumor and the mature teratomatous tissue at recurrence (case 2, Table 1), indicating clonal progression. Investigations into a large number of cases are warranted to assess the genetic relationship between the extra-ovarian metastasis including gliomatosis peritonei and the corresponding ovarian teratoma. Moreover, comparative 
genotyping studies of sacrococcygeal and CNS teratomas may provide additional insight into the pathogenesis of teratomas in general.

In summary, both immature and mature teratomas harbor frequent genetic homozygosity, implying a shared cellular origin involving germ cells at the same developmental stage. The difference in the rate of homozygosity and tumor recurrence between pure immature teratomas and mixed germ cell tumors with an immature teratoma component suggests that the two entities may involve different pathogenetic pathways and likely pursue a different clinical course.

\section{Disclosure/conflict of interest}

The authors declare no conflict of interest.

\section{References}

1 Kurman RJ, Carcangiu ML, Herrington CS, et al. (eds). WHO Classification of Tumours of Female Reproductive Organs. International Agency for Research on Cancer: Lyon, 2014;25-8:60-61 pp.

2 Linder D. Gene loss in human teratomas. Proc Natl Acad Sci U S A 1969;63:699-704.

3 Linder D, Power J. Further evidence for post-meiotic origin of teratomas in the human female. Ann Hum Genet 1970;34:21-30.

4 Eppig JJ, Kozak LP, Eicher EM, et al. Ovarian teratomas in mice are derived from oocytes that have completed the first meiotic division. Nature 1977;269:517-518.

5 Patil SR, Kaiser-McCaw B, Hecht F, et al. Human benign ovarian teratomas: chromosomal and electrophoretic enzyme studies. Birth Defects Orig Artic Ser 1978;14:297-301.

6 Surti U, Hoffner L, Chakravarti A, et al. Genetics and biology of human ovarian teratomas. I. Cytogenetic analysis and mechanism of origin. Am J Hum Genet 1990;47:635-643.

7 Deka R, Chakravarti A, Surti U, et al. Genetics and biology of human ovarian teratomas. II. Molecular analysis of origin of nondisjunction and gene-centromere mapping of chromosome I markers. Am J Hum Genet 1990;47:644-655.

8 Dahl N, Gustavson K-H, Rune C, et al. Benign ovarian teratomas. An analysis of their cellular origin. Cancer Genet Cytogenet 1990;46:115-123.

9 Vortmeyer AO, Devouassoux-Shisheboran M, Li G, et al. Microdissection-based analysis of mature ovarian teratoma. Am J Pathol 1999;154:987-991.

10 Smith HO, Berwick M, Verschraegen CF, et al. Incidence and survival rates for female malignant germ cell tumors. Obstet Gynecol 2006;107:1075-1085.
11 Ohama K, Nomura K, Okamoto E, et al. Origin of immature teratoma of the ovary. Am J Obstet Gynecol 1985;152(7 Pt 1):896-900.

12 Hoffner L, Shen-Schwarz S, Deka R, et al. Genetics and biology of human ovarian teratomas. III. Cytogenetics and origins of malignant ovarian germ cell tumors. Cancer Genet Cytogenet 1992;62:58-65.

13 Radice P, Pierotti MA, Lacerenza S, et al. Loss of heterozygosity in human germinal tumors. Cytogenet Cell Genet 1989;52:72-76.

14 Zhuang Z, Devouassoux-Shisheboran M, Lubensky IA, et al. Premeiotic origin of teratomas: Is meiosis required for differentiation into mature tissues? Cell Cycle 2014;4:1683-1687.

15 Riopel MA, Spellerberg A, Griffin CA, et al. Genetic analysis of ovarian germ cell tumors by comparative genomic hybridization. Cancer Res 1998;58: 3105-3110.

16 Poulos C, Cheng L, Zhang S, et al. Analysis of ovarian teratomas for isochromosome 12p: evidence supporting a dual histogenetic pathway for teratomatous elements. Mod Pathol 2006;19:766-771.

17 Kraggerud SM, Hoei-Hansen CE, Alagaratnam S, et al. Molecular characteristics of malignant ovarian germ cell tumors and comparison with testicular counterparts: implications for pathogenesis. Endocr Rev 2013;34:339-376.

18 Roth LM, Talerman A. Recent advances in the pathology and classification of ovarian germ cell tumors. Int J Gynecol Pathol 2006;25:305-320.

19 Kraggerud SM, Szymanska J, Abeler VM, et al. DNA copy number changes in malignant ovarian germ cell tumors. Cancer Res 2000;60:3025-3030.

20 Norris HJ, Zirkin HJ, Benson WL. Immature (malignant) teratoma of the ovary. Cancer 1976;37:2359-2372.

21 Robboy SJ, Scully RE. Ovarian teratoma with glial implants on the peritoneum. An analysis of 12 cases. Hum Pathol 1970;1:643-653.

22 Edge SB, Byrd DR, Compton CC, et al. (eds) American Joint Committee on Cancer Staging Manual, 7th edn. Springer: New York, NY, 2010.

23 Zhong H, Liu Y, Talmor M, et al. Deparaffinization and lysis by hydrothermal pressure (pressure cooking) coupled with chaotropic salt column purification: a rapid and efficient method of DNA extraction from formalin-fixed paraffin-embedded tissue. Diagn Mol Pathol 2013;22:52-58.

24 Dahl N, Gustavson KH, Rune C, et al. Benign ovarian teratomas. An analysis of their cellular origin. Cancer Genet Cytogenet 1990;46:115-123.

25 Heifetz SA, Cushing B, Giller R, et al. Immature teratomas in children: pathologic considerations: a report from the combined Pediatric Oncology Group/ Children's Cancer Group. Am J Surg Pathol 1998;22: 1115-1124.

26 Kwan MY, Kalle W, Lau GT, et al. Is gliomatosis peritonei derived from the associated ovarian teratoma? Hum Pathol 2004;35:685-688. 